\title{
DO LOCAL PARA A COMPREENSÃo DO GLOBAL: SAÚDE E AMBIENTE EM UMA PEQUENA CIDADE DA AMAZÔNIA
}

\section{LOCAL TO GLOBAL UNDERSTANDING: HEALTH AND ENVIRONMENT IN A SMALL TOWN IN THE AMAZON}

\author{
Viviana Mendes Lima' ${ }^{1}$ \\ Sandra Maria Fonseca da Costa ${ }^{2}$ \\ Jobair Assis Rangel ${ }^{3}$ \\ Gustavo Rodrigo Milaré Montoia ${ }^{4}$
}

\begin{abstract}
Resumo: Os grandes avanços da humanidade, entre eles o meio técnico-cientifico, com descobertas importantes do século XXI, contribuíram para melhorias na saúde e mitigação ou cura de algumas enfermidades. As doenças permanecem grandes desafios nas sociedades contemporâneas que apresentam novas demandas e tempo de cura. Os avanços e velocidade que acompanham a globalização refletiu-se na tomada de decisões no processo saúde-doença. Este artigo propõe apresentar uma análise sobre a situação dos moradores de um pequeno município da Amazônia, Ponta de Pedras, Pará, investigando a existência de doenças comuns aos habitantes das grandes cidades. Como metodologia, o artigo embasou-se em pesquisa bibliográfica sobre a temática apresentada, combinada à pesquisa empírica realizada no Município de Ponta de Pedras, além das bases de dados do IBGE. Como resultado, nota-se uma mudança no padrão alimentar da população local em especial da população rural, justificada por escassez de pescados e falta de poder aquisitivo para a compra de outros alimentos. Esta mudança no padrão alimentar, com presença de fast-food, somada a outros aspectos, interfere na saúde da população e contribuiu para a emergência de fatores de risco e doenças comuns em grandes cidades e metrópoles, como stress, obesidade, colesterol alto, diabetes, hipertensão arterial.
\end{abstract}

Palavras-chave: Saúde global; açaí; pequena cidade; delta; Amazônia.

\begin{abstract}
The great advances of mankind, among them the technical-scientific milieu, with important discoveries of the 21st century, contributed to improvements in health and mitigation or cure of some diseases. Diseases are the great challenges of contemporary societies that present new demands and healing time, and globalization has brought advances and speed in decision making in the health-disease process. This article proposes to present an analysis on the situation of the residents of a small municipality in the Amazon, Ponta de Pedras, Pará, regarding the existence of diseases common to the inhabitants of the big cities. As a methodology, the article was based on a bibliographical research on the topic presented, and data from the field work at the Municipality of Ponta de Pedras, besides IBGE databases. As a result, a change in the food pattern of the local population, especially the rural population, is observed, justified by shortages of fish and lack of purchasing power for the purchase of other foods, such as chickens and meats. This change in the food profile, among other aspects, has caused diseases that are very common in large cities and metropolises, such as stress, obesity, high cholesterol, diabetes and high blood pressure, caused by fast food standards that interfere with the health of the population.
\end{abstract}

Keywords: Global health; acai; small town; delta; Amazon.

\footnotetext{
${ }^{1}$ Geógrafa, Mestra em Planejamento Urbano e Regional, Doutora em Saúde Global e Sustentabilidade. Pos doutoranda em Planejamento Urbano e Regional na UNIVAP - Universidade do Vale do Paraíba. Bolsista de Produtividade CNPq, Brasil. E-mail: geolimabrasilch@yahoo.com.br.

2 Bolsista de Produtividade CNPq, Professora do Programa de Pós-Graduação em Planejamento Urbano e Regional da UNIVAP - Universidade do Vale do Paraíba, Brasil. E-mail: sandra@univap.br.

${ }^{3}$ Geógrafo, Mestre em Planejamento Urbano e Regional, Doutorando em Planejamento Urbano e Regional na UNIVAP, Pesquisador Associado do Laboratório de Estudos das Cidades, Brasil. E-mail: jobairrangel@terra.com.br.

${ }^{4}$ Geógrafo, Doutor em Planejamento Urbano e Regional e Pesquisador Associado do Laboratório de Estudos das Cidades na UNIVAP - Universidade do Vale do Paraíba, Brasil. E-mail: milaremontoia@hotmail.com.
} 


\title{
1 INTRODUÇÃO
}

A saúde global é um tema multidisciplinar e complexo, sobretudo em tempos de globalização econômica e cultural caraterizado por rápidas mudanças que têm despertado debates no campo da ciência da saúde. Fortes e Ribeiro (2014, p. 5) corroboram com essa afirmação e comentam que, diante da complexidade do conceito de saúde global, os determinantes e as possíveis soluções dos problemas necessitam de acordos globais e da inclusão de diversos atores sociais, tais como países e governos, agências e instituições internacionais públicas e privadas. A saúde global também é discutida como um campo de conhecimento, de caráter interdisciplinar que envolve práticas de ensino, pesquisas e outras abordagens territoriais e espaciais.

Sendo assim, é necessário um olhar aberto para as ações em saúde, que permitam perceber a melhor forma de intervenção no sentido de mitigar danos, em especial à população atingida por problemas nesse campo, seja em escala global ou local. Para alguns autores, o termo "saúde global" foi constituído a partir de uma abordagem internacional, descrito em algumas obras de referência. Por exemplo,

\begin{abstract}
A expressão "saúde global" é encontrada na literatura de saúde de forma significativa a partir dos anos 1990. Afirma-se que para a consolidação da expressão, utilizada como substituta de "3saúde internacional", teve grande relevância a Organização Mundial da Saúde, em virtude da renovação de seu papel enquanto instituição dedicada a coordenar questões de saúde no planeta (FORTES; RIBEIRO, 2014, p. 9).
\end{abstract}

Vale lembrar que os conceitos resultam de uma construção histórica que passaram por uma transição, à medida que novos conhecimentos foram surgindo, na característica da pesquisa acadêmica.

Segundo Matta e Moreno (2014, p. 14), com a problemática global das doenças existe a necessidade de identificar os problemas de saúde, independente de sua localização territorial/nacional, que devem ser avaliados de forma transnacional, por meio da construção/aplicação de indicadores demográficos, econômicos e epidemiológicos. Ribeiro (2016, p. 9) menciona que os princípios da saúde global, a partir da expansão da globalização, tem promovido fortes consequências sobre a demografia, a produção, o consumo, o meio ambiente e evidencia a necessidade de novas abordagens que levem em conta a relação do espaço local com o global. A partir da consideração da autora, nota-se que a Saúde Global está na pauta das agendas de políticas internacionais, pois contribui à discussão e à busca por soluções de problemas que transcendem fronteiras e provocam impacto global no desenvolvimento da população do mundo.

\footnotetext{
${ }^{3}$ O termo saúde internacional foi utilizado pela primeira vez pela Fundação Rockfeller, 1913, a qual criou a Comissão Internacional da Saúde para implementar, mundialmente, os programas de ancilostomíase e de saúde pública desenvolvidos nos Estados Unidos. Brown 1997, citado por Gomez-Dantés e Babak Khshnood, 1991, p.319
} 
Muitos autores, no campo da saúde pública ou políticas em saúde, contribuíram para a compreensão deste processo transitório conceitual. Nessa relação, constata-se que, no processo histórico das grandes transformações espaciais e crises globais, há trinta anos, com a descoberta e o tratamento da AIDS, mudou-se a concepção de se pensar a saúde de forma localizada (KICKBUCH; BERGER, 2010, p. 190). Vivemos em uma aldeia global, onde as informações são simultâneas e desterritorializaram o comportamento humano, bem como as doenças existentes, à medida que as preocupações com os impactos do processo saúde-doença se ampliam.

Ribeiro (2016, p. 9) exemplifica a perspectiva da globalização no âmbito da saúde, o aprofundamento deste processo, com fortes consequências sobre a demografia, a produção, o consumo, o meio ambiente, e reitera a necessidade de novas abordagens que levem em conta a relação do local com o global/universal.

O modo de produção global, com atendimento à economia de mercado e aumento do lucro do produtor, entre outros aspectos, tem influenciado na vida das populações de pequenas comunidades, que se conectam com esse mercado em função do atendimento à sua demanda. A pressão de produzir mais, para obter mais lucro, tem afetado trabalhadores e reproduzido, em contexto rural, doenças urbanas (LIMA; COSTA; RIBEIRO, 2018). Outro aspecto ressaltado por alguns autores é a mudança no hábito alimentar de populações rurais, influenciadas pelo modo de vida urbano, que tem causado problemas como a obesidade e doenças cardiovasculares (MURIETTA; SIQUEIRA, 1999). Essa situação pode ser verificada em várias pequenas cidades da Amazônia, pois estas apresentam-se uma conexão maior com o mercado global.

Essa internacionalização da economia trouxe problemas sociais ambientais e de saúde. Em alguns casos, esses problemas associam-se a parâmetros qualitativos, como, por exemplo, a perda da paisagem, a partir da degradação ambiental. Em outros aspectos, os impactos à saúde são diversos, em especial quando relacionados às condições de renda, acesso à educação, infraestrutura, alimentação que se refletem na expectativa de vida.

O município de Ponta de Pedras, localizado no estado do Pará, é um importante produtor de açaí, o qual é comercializado, principalmente, em Belém, e depois exportado para outras regiões do Brasil e do exterior. Ponta de Pedras colhe $12 \%$ do total de açaí produzido no Brasil (COSTA et al., 2017). O açaí inseriu o município nos cenários econômico e gastronômico, em nível nacional e global.

O açaí (Euterpe oleracea Mart.) tem sido cada vez mais utilizado na culinária nacional e internacional, sendo comercializado globalmente. A sua produção é um dos principais elementos da renda e consumo da população ribeirinha do Estado do Pará, sendo a área de várzea o sítio de ocorrência natural (AZEVEDO; KATO, 2010). 
É nesse sentido que esse artigo se estrutura, ou seja, propõe-se a apresentar uma análise a respeito da situação de saúde dos moradores deste pequeno município localizado no Delta do rio Amazonas e conectado à economia global. $O$ objeto empírico deste estudo, Ponta de Pedras, está localizada no estado do Pará.

\section{MÉTODOS DA PESQUISA}

\section{1. Área de Estudo}

A área de estudo é o município de Ponta de Pedras, formado por terra firme e várzea. Possui uma malha hídrica densa, que se altera durante as estações de verão e inverno da região, as quais interferem na dinâmica de vida dos moradores das comunidades rurais (ribeirinhos) e da cidade. Há uma grande relação econômica com a capital do Estado, Belém para compra de diversos produtos duráveis e industrializados, que abastecem o comércio local. Neste mesmo fluxo econômico, há o escoamento da produção local, de peixes, camarão, açaí, palmito e demais produtos típicos, para venda no comércio em Belém.

Ponta de Pedras é um dos 143 municípios do Estado do Pará e pode ser classificado como um pequeno município, em termos demográficos, visto que sua extensão territorial é grande para a população que o habita (figura 1). Localiza-se na Ilha de Marajó, e está distante $40 \mathrm{~km}$ em linha reta da capital, na região estuarina do Rio Amazonas, a três horas e trinta minutos viajando de barco da capital do Pará.

De acordo com o IBGE (2018), a projeção populacional para o município, em 2018, era de 30.608 mil habitantes. Os dados do Censo de 2010 (IBGE, 2018) demonstravam que $49 \%$ dos moradores residiam em área urbana e $51 \%$ na área rural. O município apresenta o Índice de Desenvolvimento Humano (IDH) de 0,562, o do Estado do Pará é de 0,675 , considerado médio, de acordo com a classificação de desenvolvimento, e o Brasil apresenta 0,768 segundo dados do IIBGE (2010). A área urbana de Ponta de Pedras, apesar de apresentar crescimento econômico, não proporciona aos seus habitantes acesso à infraestrutura básica adequada, conforme constataram os estudos de Costa et al. (2012 p. 3-4). 
Figura 1 - Localização do Município de Ponta de Pedras.

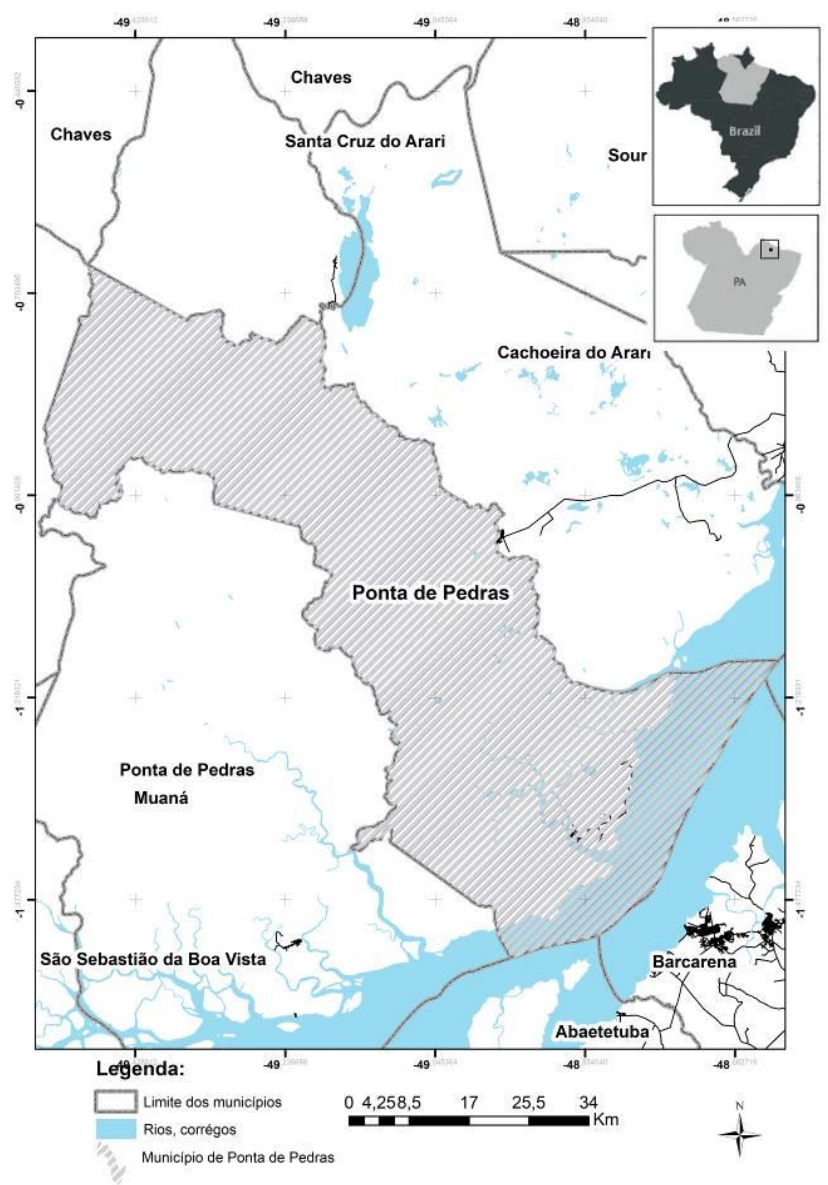

Fonte: Laboratório de Estudos das Cidades - UNIVAP (2019).

\subsection{Etapas da Pesquisa}

Os procedimentos metodológicos da pesquisa que originou o presente artigo embasaram-se em pesquisas bibliográficas a respeito da temática, levantamento de dados primários em campo e consulta a fontes secundárias. Ao longo do trabalho de campo, foram aplicados 398 formulários para moradores das áreas urbanas e rurais no município, o que representou uma amostragem de $10 \%$ da população residente nos setores censitários urbanos e rurais estudados. Por meio da aplicação dos formulários foram levantadas informações referentes ao perfil socioeconômico dos moradores, seus hábitos alimentares, condições de saúde e habitabilidade, que permitiram compreender a situação dessa população em relação ao objetivo desse estudo.

Considerando os 50 municípios que se incluem na área do Projeto DELTAS, do rio Amazonas, ao qual esse estudo se vincula. Segundo o IBGE (2010), predominam os municípios com menos de 20 mil habitantes (68\%), sendo que $86 \%$ das cidades, dessa área possuem menos de 50 mil habitantes. Ou seja, são pequenos núcleos urbanos, com fortes carências de investimento em infraestrutura e com grandes disparidades nos indicadores socioeconômicos. A tabulação desses dados permitiu 
sua compreensão e análise. Os dados primários foram obtidos por meio de pesquisa de campo, realizada no Município de Ponta de Pedras, nos meses de julho de 2014, julho de 2015, janeiro de 2016 e julho de 2016. A pesquisa foi aprovada pelo Comitê de Ética da Universidade de São Paulo, processo número 3.100.314.

Este trabalho é resultante de uma etapa de pesquisa de uma tese de doutorado, que está em expansão no Pós-doutorado. Destaca-se que este trabalho contribuirá com a compreensão das problemáticas relativas à saúde das populações residentes nas pequenas cidades da Amazônia.

\section{SAÚDE E AMBIENTE NO DELTA DO RIO AMAZONAS}

Quando se trata do global e da Amazônia, observa-se que há um grande interesse por parte dos investidores nacionais e internacionais em busca da exploração e comercialização dos recursos naturais existentes no maior ecossistema existente no mundo. Browder e Godf (2006) descrevem a Amazônia como um território em constante transformações, em especial entre 1970 e 1990, devido ao crescimento intenso das cidades. As alterações, mencionadas pelos autores supracitados, também ocorreram nas pequenas e médias cidades da Amazônia. Contudo, há de se ressaltar que muitas destas cidades não conseguiram estruturar-se de maneira adequada, para atender as demandas relacionadas aos novos fluxos comerciais e sociais.

A antropização no território e as transformações na paisagem natural foram reflexos do intenso processo migratório que se consolidou com o adensamento da população nesta região. Para Becker, à medida que a urbanização foi se intensificando, a região vivenciou um forte fluxo migratório e contínua exploração da terra. Por estas e outras justificativas, a partir da década de 1980 a autora denomina a região de "floresta urbanizada" (BECKER, 2005, p. 73).

Em relação aos fatores ambiente e saúde na Amazônia, para Lima (2018, p. 24) o fator ambiental é categórico nesta região do país, quando associado aos processos econômicos, urbanização e desmatamento. A degradação ambiental se reflete nas condições de saúde dos moradores locais, por inúmeros fatores. Como exemplo, o estudo desenvolvido por Saccaro Junior, Mation e Sakowski (2015, p. 11), no qual avaliaram o impacto do desmatamento nos municípios da Amazônia Legal e as doenças de notificação compulsória e inferiram uma relação intrínseca entre desmatamento e avanço dessas doenças. Doenças como acidentes por animais peçonhentos, doença de Chagas, dengue, esquistossomose, febre tifoide, leishmaniose tegumentar americana, leishmaniose visceral, leptospirose, malária, sarampo e rubéola têm relação direta com o desmatamento e interferem na condição de saúde da população, conforme dados da pesquisa apresentada pelos estudiosos.

Lemos e Silva (2011, p. 99) afirmam que ocorreu, na década de 1970, uma intensificação no desmatamento da Amazônia em função da ocupação urbana, 
principalmente o realizado pelo agronegócio, em consequência do projeto político estabelecido pelo governo nacional. Houve grandes incentivos de ocupação desta região por parte do governo, integrado ao projeto de internacionalização da Amazônia, entre eles a SUDAM - Superintendência do Desenvolvimento da Amazônia.

Contudo, a relação ambiente e saúde também está relacionada às desigualdades sociais, principalmente nas pequenas cidades da região amazônica, que possuem economia frágil, carência de infraestrutura básica, serviços de saúde, deficiência na oferta de emprego, entre outros. Ressalta-se que o município de estudo, localizado na Região do Delta Amazônico, apresenta os mesmos problemas de degradações ambientais e socioespaciais de outros municípios da Amazônia Legal. Por estar inserido no Delta do rio Amazonas, há preocupações ainda maiores. Em estudos sobre mudanças climáticas, desenvolvidos pelos pesquisadores Fenzl e Robrini (2013, p. 11), foram expostos efeitos preocupantes quanto à elevação do nível do mar no entorno das margens Norte e Leste da llha do Marajó, com vulnerabilidade à influência das marés e ao processo de erosão. Estas ações climáticas, somadas aos fatores de baixo desenvolvimento, descritos anteriormente, resultam em problemas relacionados à saúde, em especial da população residente das áreas vulneráveis. Segundo Porto (2012),

Os riscos à saúde e ao meio ambiente decorrentes do desenvolvimento econômico e tecnológico, estejam presentes nos ambientes onde as pessoas trabalham, moram ou circulam, podem ser pouco graves. Mas o maior perigo reside justamente quando as pessoas (...), comunidades e a sociedade como um todo, expostas a ele não são capazes de enfrentá-lo e analisá-lo, adequadamente, intervindo em suas origens mais profundas (PORTO, 2012, p. 33).

Para Brondízio et al (2016, p. 26), as regiões do Delta constituem ambientes ecológicos e sociais dinâmicos, além de contribuírem para as economias nacionais. $O$ Delta do Amazonas tem significado local e global por conglomerar uma série de condições biofísicas e sociais. Sendo assim, nas observações dos autores, o processo de transformação sócio-espacial vivenciado pelo ecossistema é inquietante, considerando que é fonte de recursos econômicos, de geração de renda, de alimentos, de caça e pesca para muitos moradores.

\subsection{As pequenas cidades da Amazônia no contexto global}

Algumas características definem as pequenas cidades nesta região, constatado por Oliveira (2004, p. 3-4,) que afirma que o primeiro critério ainda é o demográfico, contudo outros são agregados a este atributo: 1. Baixa articulação com as cidades do entorno; 2. Atividades econômicas quase nulas com predomínios dos trabalhos ligados aos serviços públicos; 3. Baixa capacidade de oferecimento de serviços, mesmo os básicos ligados à saúde, educação e segurança; 4. Predominância de atividades caracterizadas como rurais. Para o autor, na região, as políticas e planos 
desenvolvimentistas estiveram centradas em atender 0 novo perfil urbano da Amazônia, resultante dos projetos estatais e privados com o objetivo de urbanizar e desenvolver a Região.

Acompanhando essa reflexão, Trindade Junior (2013, p. 12-13) analisa que a concepção, dinâmica e forma de articular o local com o global, das pequenas cidades e seus conteúdos mais enraizados, são responsáveis, igualmente, por caracterizar esses núcleos urbanos como cidades pequenas, mas não necessariamente como cidades locais, dada a pouca interação e respostas às necessidades e demandas do entorno. Associado a esta interconexão na formação das pequenas cidades, alguns estudos entre saúde e ambiente, na Amazônia, têm despertado questionamentos relacionados aos diferentes modos de uso da terra, fauna e flora e ao perfil de saúde da população. Conhecer o perfil de saúde na pequena cidade amazônica cada vez mais inserida no contexto global, com a produção e extração de recursos naturais, e em intenso processo histórico de urbanização permitirá avaliar mudanças no perfil epidemiológico de adoecimento, com consequências no nível de saúde e qualidade de vida, em especial para os países com populações vulneráveis e baixo poder aquisitivo.

\subsection{Do Global ao Local e a Condição de Saúde da População de uma Pequena Cidade da Amazônia}

Um novo perfil epidemiológico de doenças caracteriza alguns países, como reflexo do apagamento das fronteiras espaciais e terrestres. Doenças antes controladas $^{4}$ como sarampo, poliomielite, ebola, rubéola, difteria, associadas à pobreza, voltaram a causar mortes, em cenários e situações complexos. A revisão bibliográfica realizada por Araújo-Jorge et al (2014, p. 3), a respeito deste perfil epidemiológico mostra que, junto aos agravos prevalentes no Brasil como diarreias, doenças infecciosas e desnutrição, dentre outras condições negligenciadas ${ }^{5}$ características da pobreza. A Organização Mundial da Saúde (OMS, 2018) estabelece diretrizes de redução para algumas doenças globais, como cardiovasculares, obesidade, diabetes, hipertensão e câncer. Dados da VIGITEL BRASIL (BRASIL, 2017) e OMS (2018) apresentam números expressivos de casos de câncer $(542,140$

\footnotetext{
${ }^{4}$ Em 1948, a OMS assumiu a responsabilidade pela Classificação Internacional de Doenças, que se tornou o padrão internacional para fins clínicos e epidemiológicos. Entre 1952 e 1964, os esforços da OMS já haviam reduzido a prevalência global de bouba - deficiência física que afligia cerca de 50 milhões de pessoas em 1950 - em mais de 95\%. Entre 1967 e 1979, os esforços da OMS levaram à erradicação da varíola - única vez em que uma das principais doenças infecciosas foi completamente erradicada. Desde que a sua Iniciativa Global de Erradicação da Pólio foi lançada em 1988, até 2006, o número de casos foi reduzido em mais de $99 \%$ - de 350 mil por ano para menos de dois mil (ONUBR - ORGANIZAÇÃO DAS NAÇÕES UNIDAS BRASIL, 2018).

${ }_{5}$ Doenças negligenciadas são doenças que não só prevalecem em condições de pobreza, mas também contribuem para a manutenção do quadro de desigualdade, já que representam forte entrave ao desenvolvimento dos países. Como exemplos de doenças negligenciadas, podemos citar: dengue, doença de Chagas, esquistossomose, hanseníase, leishmaniose, malária, tuberculose, entre outras (2010 Brasil - Decit - Departamento de Ciência e Tecnologia do Ministério da Saúde).
} 
mil) referindo-se a todos os tipos de neoplasias, diabetes ${ }^{6}$ (16 milhões) e hipertensão (36 milhões)

Essas informações convidam a pensar a saúde no contexto global e refletir sobre os aspectos que se relacionam ao local, e, no caso deste artigo, em como tais fatores interferem na saúde das populações e na dinâmica das pequenas cidades da Amazônia. Neste sentido, Ponta de Pedras, tanto no contexto rural quanto no urbano, apresenta problemas de esfera global que alteram a dinâmica local. Um exemplo é o aumento do número de casos de algumas doenças e sintomas como diarreias, virose, relacionadas ao difícil acesso à água de qualidade, ausência de tratamento de esgoto, entre outros aspectos, estas informações foram colhidas por meio de formulários aplicados em campo. Quanto ao despejo do esgoto, a prática mais comum segundo relatos dos entrevistados é o descarte no igarapé, contaminando o rio e o manancial, uma vez que esta água é muita utilizada pelos os moradores para diversas finalidades domésticas, sendo assim o risco de transmissão de doenças torna-se maior. Na área urbana, $43 \%$ dos moradores têm essa prática, e na área rural $82,6 \%$, justificável pela precariedade do sistema de coleta de esgoto. A fossa séptica é a segunda opção de descarte do esgoto para $32 \%$ dos domicílios da área urbana, sobretudo, para moradores de terra firme.

Estudos realizado por Kronemberger (2013, p. 5), ao avaliar a relação saúde, ambiente e saneamento, verificou ônus com a ausência de saneamento:

\begin{abstract}
Em 2010, os baixos índices de coleta de esgotos foram acompanhados por altas taxas de internação por diarreias em 60 de um total de 100 cidades pesquisadas. Entre as 20 cidades com menor taxa de internação, em média, $78 \%$ de população é atendida por coleta de esgotos. Por outro lado, nas dez cidades com maiores taxas de internação, tem-se cerca de $29 \%$ de população atendida por coleta de esgotos. Os resultados do estudo reforçam a constatação de que as crianças são as mais vulneráveis. Nas 100 cidades analisadas, foram registradas 28.594 internações de crianças de até 5 anos, ou seja, $53 \%$ do total das internações no Brasil (54.339). O total de internações custa cerca de $\mathrm{R} \$ 140$ milhões por ano ao Sistema Único de Saúde (SUS).
\end{abstract}

Giatti (2009) ressalta que, no processo saúde-doença, os aspectos ambientais frequentemente se integram aos mecanismos de transmissão das moléstias de forma direta ou indireta. No caso do município desta pesquisa, pode-se citar, além do acesso à água, o ambiente de moradias precárias, localizadas nas áreas de várzeas, como fatores que comprometem a saúde dos moradores. Dados da Organização Mundial da Saúde (OMS), afirmam que $88 \%$ das mortes por diarreias no mundo são causadas pelo saneamento inadequado. Dessas mortes, aproximadamente $84 \%$ são de

\footnotetext{
${ }^{6}$ A Organização Mundial da Saúde (OMS) divulgou quais são as prioridades da saúde para 2019. Dentre elas, destaca-se o controle de doenças crônicas não transmissíveis, como diabetes que, só no Brasil, atinge mais de 13 milhões de pessoas (OMS, 2018). A diabetes é uma epidemia global e o Brasil ocupa o 4 lugar no ranking dos países com o maior número de casos, atrás de China, Índia e Estados Unidos. Doenças cardiovasculares, respiratórias crônicas, diabetes e câncer respondem por $74 \%$ dos óbitos e a primeira causa de mortes no Brasil (VIGITEL BRASIL 2018).
} 
crianças, sendo a segunda maior causa de mortalidade em menores de 5 anos. Estima-se que 1,5 milhão de crianças nessa faixa etária morram a cada ano vítimas de doenças diarreicas. Ressalta-se que a ausência dos serviços de saneamento básico é responsável por grande parte das doenças parasitárias no Brasil e no mundo. No caso brasileiro o prejuízo econômico do sistema de saneamento precário ou ausente, sobrecarrega os cofres públicos: a cada U\$1 gasto com tratamento de esgoto, são economizados U\$ 4 em atendimento de saúde (CANCIAN; LADEIRA, 20197). Ademais, melhora o Índice de Desenvolvimento Humano (IDH), um importante indicador estabelecido nas diretrizes e metas socioeconômicas a serem atingidas, até 2015 na agenda dos Objetivos de Desenvolvimento do Milênio. Cabe ressaltar que estes problemas ocorrem também em outros países como África e Ásia com características próximas ao do Brasil.

Muito se avançou nas descobertas e tratamentos das doenças de impacto global, mas, em escalas locais, há grandes desafios ainda, sobretudo em lugares com poucos recursos financeiros e tecnológicos, como no caso de Ponta de Pedras.

\section{A ECONOMIA dO AÇAÍ E A SAÚdE DA POPULAÇÃO NO MUNICÍPIO DE PONTA DE PEDRAS.}

Como mencionado, o município tem sua base econômica na piscicultura e na produção de açaí, sendo esta última atividade extrativista ${ }^{8}$ de grande relevância econômica e social da cadeia produtiva do Estado, o que garante a geração de emprego e renda à população local e demais produtores. Em pesquisa realizada, Lima (2017, p. 129) constatou que ao considerar os dados da renda na forma cruzada, notase que muitos moradores da área rural alegam possuírem mais que uma fonte de renda, relacionadas com a produção e comercialização do açaí. $\mathrm{Na}$ área rural são $89,8 \%$ e na área urbana $11,3 \%$, sobre o total dos entrevistados.

Com a internacionalização do açaí, alterou-se não apenas o contexto econômico, cultural e social na cidade, ampliou-se a complexidade dos fatores de risco e doenças, às quais a população está exposta. Doenças que anteriormente eram consideradas de âmbito global, estão presentes em pequenas cidades como Ponta de Pedras. Doenças relacionadas ao stress dos grandes centros urbanos, como diabetes, hipertensão arterial, distúrbios do metabolismo de lipídios entre outras enfermidades e condições influenciadas por hábitos alimentares inadequados e falta de atividades, estão presentes na população da pequena cidade da Amazônia (LIMA, 2017, p. 58).

\footnotetext{
7 "Em cinco anos, doenças por falta de saneamento custam R\$ 1 bi ao SUS". Reportagem da Folha de São Paulo. Disponível em < https://www1.folha.uol.com.br/cotidiano/2019/10/em-cinco-anos-doencas-por-falta-de-saneamentocustam-r-1-bi-ao-sus.shtml> Acesso em 20.jul.2019.

8 A produção do açaí é considerada atividade extrativista, portanto não recolhe ICMS, conforme prevê a Lei Complementar no 24 , de 7 de janeiro de 1975, Convênio ICMS 66/94, de 30 de junho de 1994 e Convênio ICMS 99, de 6 de setembro de 2017.
} 
Ademais, Lima (2017) afirma que em 17\% dos domicílios urbanos e em $21 \%$ na zona rural os moradores relataram diagnóstico médico de hipertensão arterial. Em relação ao Colesterol elevado, em $8 \%$ dos domicílios, na zona urbana, e em $7 \%$ na zona rural, os moradores relataram sofrer com o agravo das condições de saúde, mesmo fazendo o tratamento por acompanhamento médico. Mas necessita-se de uma atividade física associada a uma dieta alimentar, o que muitos alegaram não ter condições para fazer. Outra doença informada pelos moradores foi diabetes, presente em $6 \%$ dos domicílios da área urbana e $4 \%$ da área rural. Observa-se que doenças comumente referidas na literatura para esses ambientes ribeirinhos, como diarreia e malária, pouco foram mencionadas pelos moradores locais.

No entanto, quando questionados sobre o que estaria ocasionando estas doenças, as pessoas entrevistadas alegaram que a alteração do clima seria um fator em especial, por desmatarem a vegetação natural para o manejo do açaí e outras atividades locais, como construções de habitações. A segunda justificativa emitida pelos moradores entrevistados, destacou a má alimentação, que possui grande influência nas condições de saúde, e nas enfermidades referidas (hipertensão, diabetes e níveis de colesterol elevado).

Sabe-se da importância do aporte intersetorial, cada vez mais necessário entre as instituições e os países, quando o assunto é saúde. Os avanços da técnica e da ciência permitem estudar e conhecer melhor as intervenções no ambiente, com o objetivo de mitigar danos causados à população exposta. Sabe-se que na Amazônia o abastecimento e qualidade de água são precários, assim como os hábitos de higiene e os ambientes insalubres e vulneráveis. Essas informações também foram registradas pelos entrevistados como fatores causadores, responsáveis por muitas doenças, além das mudanças nos hábitos alimentares no cotidiano.

Estudos de Costa e Schor (2013, p. 209) assinalam que a população ribeirinha tem mudado seu padrão alimentar, como reflexo das transformações sociais, econômicas e culturais complexas, a partir do processo de urbanização.

Os dados coletados nos trabalhos de campo realizados (LIMA, 2017), sugerem uma influência do global no local, relacionada à substituição dos hábitos alimentares tradicionais por alimentos industrializados e ultraprocessados. Murrieta e Siqueira (1999) estudaram os hábitos alimentares em três comunidades da llha do Marajó, no município de Ponta de Pedras, com objetivo de compreender o padrão alimentar das famílias. Os autores estudaram a dieta das comunidades, entre elas Marajó-Açú, de 1990 a 1991, e constaram que a dieta local, naquele momento, era baseada em farinha de mandioca, uma diversidade de pescados, camarões, peixes, porco e frutas locais, em especial o açaí. Os autores encontraram um consumo de ingestão diária de proteína maior do que o preconizado pelos parâmetros da FAO - Food and Agriculture Organization of the United Nations (MURRIETA; SIQUEIRA, 1999, p. 468). 
Comparando-se a pesquisa desenvolvida nos anos 1990, aos dados coletados na pesquisa empírica de campo descrita neste artigo, (LIMA, 2017) nota que a alimentação dos moradores, cuja base alimentar era predominantemente tradicional, está sendo modificada, em particular nas comunidades rurais de Ponta de Pedras. Questionados a propósito da sua preferência pelos alimentos, os moradores afirmam que o açaí é o principal complemento alimentar e que não pode faltar nas refeições diárias. Para os moradores entrevistados, o açaí consumido, chega até as suas residências por meio da coleta/extração, assim como o palmito. Os demais alimentos consumidos, como os industrializados e ultra processados, são adquiridos em comércios locais.

Ao estudar a respeito desta temática e comparar com os resultados obtidos em pesquisa de campo, observou-se a manutenção do padrão alimentar entre os adultos mantendo o consumo como açaí, peixe, farinha de mandioca. Entretanto, constatou-se que entre os mais jovens, aqueles com menos de 15 anos, o consumo de alimentos está sendo alterado pelo consumo de alimentos industrializados. Muitos moradores, durante a aplicação dos formulários em campo, justificaram, o aspecto econômico para a aquisição dos alimentos industrializados, alegando que esses produtos são mais acessíveis ao seu poder de compra. Na zona rural, observou-se também, por parte dos moradores ribeirinhos, uma insatisfação ao relatar uma escassez de pescados, devido à falta de preservação ambiental. Outros entrevistados expuseram que, em tempos outrora, havia uma grande fartura no período de pesca, contudo na atualidade afirmam dificuldades de obterem a quantidade mínima para o consumo familiar.

É válido esclarecer que mudanças geracionais nos hábitos alimentares saudáveis, podem comprometer a saúde e por sua vez a qualidade de vida dos consumidores. Nota-se que a população jovem pontapedrense tem aderido à prática do consumo de alimentos industrializados e ultraprocessados de forma contínua, conforme constado nos dados obtidos pelos formulários aplicados durante a pesquisa de campo. Dos entrevistados $47 \%$ consomem carne de vaca e frango, uma vez por semana. Em relação aos embutidos há uma inserção no cardápio alimentar de $15 \%$ da população urbana e $25 \%$ e do rural que se alimentam respectivamente, uma vez por semana destes produtos.

Quando se analisa os dados obtidos em campo, percebe-se uma população que possui uma identidade com o lugar onde mora e o desejo de ver melhorias, avanços, mas sem perder a natureza existente como a biodiversidade.

\section{CONSIDERAÇÕES FINAIS}

O município de Ponta de Pedras, no Delta Amazônico, apresenta carências de infraestrutura e de serviços, como o acesso à saúde e a educação. Por se destacar 
como um dos maiores produtores de açaí do país, foi inserido no contexto da internacionalização, devido à exportação global deste produto para mais de vinte países, entre eles EUA, Itália, Japão, Espanha. Nesse sentido, esse artigo apresentou dados relevantes que corroboram na temática de como o processo de globalização e a inserção do município de Ponta de Pedras, no contexto da economia global por meio da produção e comercialização do açaí, modificam a cultura e a saúde dos habitantes. Neste caso a saúde passa por novos hábitos de consumo alimentares, entre eles os ultraprocessados e embutidos que não são saudáveis do ponto de vista nutricional, por apresentarem grande taxas de sódio, gorduras e condimentos, o que interfere no perfil de saúde da população consumidora.

Há de se ressaltar que os ganhos obtidos com a comercialização do açaí não se converteram em benefícios para a população, pois a produção e comercialização do fruto estão classificadas como isentos de tributos fiscais. Nota-se que o crescimento econômico combinado à persistência das disparidades sociais, interfere, negativamente, nas condições de saúde da população, a qual está exposta à oferta de alimentos ultraprocessados, que gradativamente substituem a alimentação tradicional destas populações ribeirinhas.

O município de Ponta de Pedras encontra-se inserido na economia global, entretanto muitos moradores permanecem às margens das desigualdades sociais por viverem em condições precárias de moradia e com dificuldade de acesso aos equipamentos públicos.

As mudanças dos hábitos alimentares promovidos pela globalização dos produtos industrializados e ultraprocessados, têm sido inseridos no padrão alimentar e no cotidiano dos moradores desta pequena cidade Amazônica. Mesmo sendo considerada uma pequena cidade e inserida no padrão da periferia do mundo capitalista e globalizado, as tendências e os novos padrões de consumo, promovidos pela indústria alimentar, têm provocado uma alteração na saúde da população que aderiu a este padrão de consumo.

Em relação às condições de habitabilidade das áreas urbana e rural, identificouse determinados ambientes insalubres para a saúde dos seus moradores, o que interfere na qualidade de vida dos que ali residem. Estas circunstâncias precisam serem investigadas pelo poder público, visto que essas realidades ocasionam inúmeros problemas para a população e gestão local. Deve-se, sempre, em políticas públicas, pensar na redução dos danos, em especial os considerados de aspectos socioespaciais. Desta forma, notam-se transformações importantes no quadro de saúde dos moradores, quando parcela desta população opta por mudanças no padrão alimentar, de alimentos locais, considerados saudáveis, como o açaí, farinha de tapioca, peixe, camarão, e frutos típicos da região, por uma alimentação inadequada e de risco. 
Os resultados apresentados pelo presente estudo indicam uma alteração nos indicadores de saúde, como prevalência de hipertensão, diabetes e aumento dos níveis séricos de colesterol, entre outras enfermidades. Cabe ressaltar que este trabalho, por ser parte de um estudo em andamento, não se exaure neste artigo, pois muito ainda deverá ser investigado a fim de contribuir para a compreensão da situação da saúde da população das pequenas cidades da Amazônia brasileira.

\section{Agradecimentos}

Os autores agradecem a CAPES (Comissão de Aperfeiçoamento de Pessoal de Nível Superior), ao CNPq (Conselho Nacional de Desenvolvimento Científico e Tecnológico) e à FAPESP (Fundação de Amparo à Pesquisa do Estado de São Paulo) pelo apoio financeiro fornecido a esta pesquisa por meio da cessão de recursos financeiros, bolsa de produtividade, bolsa de doutorado e de pós-doutorado e UNIVAP - Universidade do Vale do Paraíba.

\section{REFERÊNCIAS}

ARAÚJO-JORGE T, Matraca M. et al. Doenças negligenciadas, erradicação da pobreza e o plano Brasil sem Miséria. In: Campelo T, Falcão T, Costa P (orgs.). 0 Brasil sem Miséria. Brasília: MDS; 2014. p. 703-726. Disponível em: <http://www.agencia.fiocruz.br/doen\%C3\%A7as-negligenciadas>. Acesso em: 26 set. 2014.

AZEVEDO, James Ribeiro; KATO, Oswaldo Ryohei. Sistema de manejo de açaizais nativos praticado por ribeirinhos das ilhas de Paquetá e ilha grande, Belém: Embrapa, 2010.

BRASIL. Ministério da Saúde. (VIGITEL). Secretaria de Vigilância em Saúde. Departamento de Vigilância de Doenças e Agravos não Transmissíveis e Promoção da Saúde. Vigitel Brasil 2016: vigilância de fatores de risco e proteção para doenças crônicas por inquérito telefônico: estimativas sobre frequência e distribuição sociodemográfica de fatores de risco e proteção para doenças crônicas nas capitais dos 26 estados brasileiros e no Distrito Federal em 2016. Brasília: Ministério da Saúde, 2017. 160p.: il. Disponível em:

$<$ http://portalarquivos2.saude.gov.br/images/pdf/2018/marco/02/vigitel-brasil2016.pdf>.

BECKER, Berta Koiffman. Geopolítica da Amazônia. Estud. av., São Paulo, v. 19, n. 53, p. 71-86, abr. 2005. Disponível em:

$<$ http://www.scielo.br/scielo.php?script=sci arttext\&pid=S0103$40142005000100005 \&$ lng=pt\&nrm=iso >. Acesso em: 29 jan. 2017.

BRONDIZIO, Eduardo S. et al. A conceptual framework for analyzing deltas as coupled social-ecological systems: an example from the Amazon River Delta. Sustain Sci., v. 11, n. 4, p. 1-19, 2016.

BROWN, P. The WHO strikes mid-life crisis. New scientist, v. 153, p. 12, 1997. 
BROWDER, John O.; GODF Brian J. Cidades na Floresta: urbanização, desenvolvimento e globalização na Amazônia Brasileira. Manaus: EDUA, 2006.

CANCIAN, N.; LADEIRA, P. Em cinco anos, doenças por falta de saneamento custam $\mathrm{R} \$ 1$ bi ao SUS. Folha de São Paulo, 2019. Disponível em:

<https://www1.folha.uol.com.br/cotidiano/2019/10/em-cinco-anos-doencas-por-falta-desaneamento-custam-r-1-bi-ao-sus.shtml> Acesso em: 20.jul. 2019.

COSTA, S. M. F. et al. A relação entre a economia do açaí e crescimento urbano em uma pequena cidade do estuário do rio Amazonas: uma reflexão. Revista Geográfica Venezolana, Mérida, v. 58, n. 1, p.10-25, 2017. Disponível em:

<http://www.saber.ula.ve/bitstream/123456789/43788/1/art\%201.pdf>. Acesso em: 22 out. 2017.

COSTA, Sandra Maria Fonseca da et al. Pequenas cidades do estuário do Rio Amazonas: fluxo econômico, crescimento urbano e as novas velhas urbanidades da pequena cidade de Ponta de Pedras. Redes (Santa Cruz do Sul. Online), v. 17, n. 2, 2012.

COSTA, Ellen A. C.; SCHOR, Tatiana. Redes Urbanas, Abastecimentos e o café da manhã de idosas na cidade de Tefé, Amazonas: Elementos para a análise da Geografia da Alimentação no Brasil. Hugeia, v. 9, n.17. p. 52-73, 2013.

FENZL, Norbert, ROBRINI, Maâmar. Projeto gestão integrada e sustentável dos recursos hídricos transfronteiriços na bacia do rio amazonas, considerando a variabilidade e mundança climática otca/gef/pnuma. Rio Branco: OTCA, 2012. Disponível em: <http://otca.info/gef/uploads/documento/81609-

ATIVID.III.2.3_MAAMAR.ROBRINI_RELATORIO_3.pdf >. Acesso em: $20 \mathrm{fev} 2019$.

FORTES, Paulo Antônio de Carvalho, RIBEIRO, Helena. Saúde Global. Barueri., SP. Editora Manole, 2014.

GIATTI, Leandro Luiz. (org). Fundamentos das relações entre saúde e ambiente. In: GIATTI, Leandro Luiz. Fundamentos de Saúde Ambiental. Manaus: Editora UFAM, 2009.

IBGE - Instituto Brasileiro de Geografia e Estatística. Censo online. 2010. Disponível em: <http://www.ibge.gov.br>. Acesso em: 10 nov. 2010.

IBGE - Instituto Brasileiro de Geografia e Estatística. Panorama das cidades. 2018. Disponível em: <https://cidades.ibge.gov.br/brasil/am/manaus/panorama>. Acesso em: 20 out. 2019.

KRONEMBERGER, Denise. Análise dos Impactos na Saúde e no Sistema Único de Saúde Decorrentes de Agravos Relacionados a um Esgotamento Sanitário Inadequado dos 100 Maiores Municípios Brasileiros no Período 2008-2011.

2013. Disponível em: <http://www.tratabrasil.org.br/datafiles/uploads/drsai/RelatorioFinal-Trata-Brasil-Denise-Versao-FINAL.pdf>. Acesso em: 20 maio 2019.

KICKBUSCH, I.; BERGER, C. Diplomacia da Saúde Global. RECIIS - Rev. Eletr. de Com. Inf. Inov. Saúde, Rio de Janeiro, v. 4, n. 1, p. 148-164, mar. 2010.

LEMOS, A. L. F.; SILVA, J. A. Desmatamento na Amazônia Legal: Evolução, Causas, Monitoramento e Possibilidades de Mitigação Através do Fundo Amazônia. Floresta e 
Ambiente, Rio de Janeiro, p. 98-108, 2011. Disponível

em:<http://www.floram.org/files/v18n1/v18n1a11.pdf> Acesso em: 20 maio 2016.

LIMA, Viviana Mendes. Globalização e saúde na Amazônia um estudo de uma pequena cidade: Ponta de Pedra, Ilha do Marajó, Pará. 2017. 200f. Tese (Doutorado em Ciências Ambientais) - Universidade de São Paulo, São Paulo, 2017.

LIMA, Viviana Mendes; COSTA, Sandra M. F.; RIBEIRO, Helena. Globalization and Health in a Small Town in the Amazon Region. In CLABORN, David. (org). Current Issues in Global Health. Londres: Editora. IntechOpen, 2018. p.1-19.

Disponível em: <https://www.intechopen.com/books/current-issues-in-global-health>. Acesso em: 20 jan. 2019.

MATTA, Gustavo Corrêa; MORENO, Arlinda Barbosa. Saúde global: uma análise sobre as relações entre os processos de globalização e o uso dos indicadores de saúde. Interface - Comunicação, Saúde, Educação [online], v. 18, n. 48, p. 09-22, 2014.

MURRIETA, R.; SIQUEIRA, A. D. Food consuption and substence in three populations on Marajó Island, Amazonia, Brazil. Human Ecology, v. 27, n. 3, p. 455-475, 1999.

OLIVEIRA, Aldemir de. A cultura nas (das) pequenas cidades da Amazônia Brasileira. In: CONGRESSO LUSO-AFRO-BRASILEIRO DE CIÊNCIAS SOCIAIS, 8, Coimbra, 2004. Anais..., Coimbra, 2004. Disponível em:

<https://www.ces.uc.pt/lab2004/inscricao/pdfs/painel74/JoseAldemirdeOliveira.pdf>. Acesso em: 27 jan. 2019.

OMS - ORGANIZAÇÃO MUNDIAL DA SAÚDE. Número de adultos com diabetes quadruplicou desde 1980, 2018. Disponível em:

<http://agenciabrasil.ebc.com.br/internacional/noticia/2016-04/oms-numero-de-adultoscom-diabetes-quadruplicou-desde-1980>. Acesso em: 20 jan. 2019.

ONUBR. Organização das Nações Unidas. A ONU e a saúde. Disponível em $<$ https://nacoesunidas.org/acao/saude/>. Acesso em: 10 nov. 2018.

PORTO, Marcelo Firpo de Souza. Uma ecologia política dos riscos: princípios para integrarmos o local e o global na promoção da saúde e de justiça ambiental. Rio de janeiro: Editora FIOCRUZ, 2012.

RIBEIRO, Helena. Saúde Global: olhares do presente. Rio de Janeiro: Editora FIOCRUZ, 2016. 106 p. (Coleção Temas em Saúde).

SACCARO JUNIOR, Nilo Luiz; MATION, Lucas Ferreira; SAKOWSKI, Patrícia Alessandra Morita. Impacto do desmatamento sobre a incidência de doenças na Amazônia. Rio de Janeiro: Ipea, 1990.

TRINDADE JÚNIOR, Saint-Clair Cordeiro da. Das "Cidades na Floresta" às "Cidades da Floresta": Espaço, Ambiente e Urbanodiversidade na Amazônia Brasileira. NAEA O Núcleo de Altos Estudos Amazônicos, n. 321, p. 1-22, 2013. Disponível em $<$ http://www.naea.ufpa.br/naea/novosite/index.php?action=Publicacao.arquivo\&id=345 >. Acesso em: 10 abr. 2019. 